\title{
The problem of tricyclic antidepressant poisoning
}

\author{
Peter Crome \\ M.B., M.R.C.P.
}

\author{
Belinda Newman \\ B.A., M.Sc.
}

\author{
Poisons Unit, Guy's Hospital, London SEI 9RT
}

\begin{abstract}
Summary
In the year May 1976 to April 1977, 489 enquiries about the management of tricyclic antidepressant poisoning received at the London Centre of the National Poisons Information Service were followed-up. One hundred and sixty-four patients $(33.5 \%)$ were unconscious, convulsions occurred in $62(12.7 \%)$, hypotension in $31(6.3 \%)$, respiratory depression in 28 $(5.7 \%)$, tachydysrhythmias in $17(3.5 \%)$ and cardiac arrest in 12 patients $(2.5 \%)$. Sixteen patients died $(3.3 \%)$. No statistically significant differences were found between individual antidepressants although poisoning with amitriptyline-like drugs resulted in a significantly higher proportion of unconscious patients than poisoning with imipramine-like drugs $(P<0.01)$. There were more asymptomatic children than adults and more unconscious adults than children. Tricyclic antidepressant poisoning is a major clinical problem in general medical and paediatric practice.
\end{abstract}

\section{Introduction}

So-called tricyclic antidepressants were introduced into clinical practice 20 years ago (Kuhn, 1958). Since then the number of cases of overdose from these drugs has increased steadily so that today 10000 patients (or $10 \%$ of all overdoses) are admitted each year to hospital in England and Wales for this reason. The relative frequencies of the various clinical features have been described in a number of series (Goel and Shanks, 1974; Brown, Dwyer and Stocks, 1971; Fournier, 1973; Bismuth et al., 1969; Noble and Matthew, 1969; Thorstrand, 1976; Fréjaville et al., 1965, 1966; Sedal et al., 1972; Serafimovski et al., 1975; Biggs et al., 1977; Noto, Robert and Hanote, 1970; Christensen and Andersen, 1977). Anti-cholinergic effects, pyramidal signs and sinus tachycardia occur commonly but coma, convulsions, respiratory depression, electrocardiographic abnormalities and myocardial depression may all ensue.

There has been only one large study of tricyclic antidepressant poisoning in adults in the United Kingdom, by Noble and Matthew (1969). They reported 100 such consecutive admissions to the

* Address for correspondence: Dr P. Crome, New Cross Hospital, Avonley Road, London SE14 5ER.
Edinburgh Poisons Treatment Centre. Their conclusions were that most of these patients were not severely affected and that recovery was usually rapid and uneventful, supportive treatment being all that was necessary. In their study no patients required artificial ventilation and there were no deaths. It seemed possible to the present authors that those findings no longer held true, for since then both the number of different antidepressants and the number of admissions to hospital have increased. Support for this view comes in a study from the same unit which reported that the proportion of patients admitted with poisoning from these drugs who wer $\mathbb{D}$ in Grade IV coma had increased from $3.9 \%$ in the्ष 5 years $1967-71$ to $15.8 \%$ in the period $1972-7 \% \frac{\mathbb{Q}}{3}$ (Proudfoot and Park, 1978). It was therefore decidee that there was a need for a further survey to assess what proportion of patients were severely affected $\overrightarrow{0}$ whether age had any influence on the incidence of co symptoms and whether any one antidepressant wast more toxic than another.

\section{Method}

This study covered the year May 1976 to April 1977. During this period all enquiries received at the London Centre of the National Poisons Information Service at Guy's Hospital about the management of tricyclic antidepressant poisoning were followed-up, using a specially designed questionnaire. A second and third request for information was made when necessary. Any patient who had taken a tricyclic drug as only a minor part of a mixed drug overdose was excluded. Patients ingesting maprotiline were included in the study for, although described as a tetracyclic antidepressant, it is chemically and pharmacologically related to the tricyclic group (Pinder et al., 1977).

The following information (wherever possible) was recorded on each patient: age and sex, drug and amount ingested, source of antidepressants, symptoms, treatment and outcome. This information was then coded to facilitate computer analysis but excluding any details which might have identified the patient. Differences between groups were compared using the $\chi^{2}$ test. 
TABLE 1. Age and sex distribution in 485 patients with tricyclic antidepressant poisoning

\begin{tabular}{lcccccccccccc}
\hline Sex & 1010 & \multicolumn{10}{c}{ Age (years) } \\
\hline & $<5$ & $5-9$ & $10-14$ & $15-19$ & $20-29$ & $30-39$ & $40-49$ & $50-59$ & $60-69$ & $70-79$ & Total \\
Male. & 49 & 11 & 6 & 10 & 53 & 33 & 12 & 9 & 3 & 2 & 188 \\
Female & 40 & 1 & 10 & 44 & 66 & 60 & 41 & 18 & 11 & 6 & 297 \\
Total & 89 & 12 & 16 & 54 & 119 & 93 & 53 & 27 & 14 & 8 & $485^{*}$ \\
\hline
\end{tabular}

* Excludes 3 patients whose age was not stated and one patient whose sex was not stated.

\section{Results}

During the 12 months of the survey there was a total of 1083 enquiries about tricyclic antidepressant poisoning and satisfactory completed questionnaires were received on 489 patients $(45 \cdot 1 \%)$. These 489 patients are discussed below.

\section{Age and sex distribution}

The age and sex distribution of the patients is shown in Table 1 . The 2 decades with most patients were $20-29$ years old $(24 \cdot 5 \%)$ and $0-10$ years old $(20 \cdot 8 \%)$. Boys outnumbered girls by $1 \cdot 3: 1$ whereas in adults ( $>15$ years old) the position was reversed, with women outnumbering men by $2: 1$.

\section{Drugs ingested}

Amitriptyline was by far the commonest drug ingested (203 patients, $41.5 \%$ ). The others, in order of frequency, were: dothiepin 70 patients $(14.3 \%)$, imipramine $68(13.9 \%)$, maprotiline 48 patients $(9.8 \%)$, nortriptyline and trimipramine 27 patients each $(5.5 \%)$, clomipramine 22 patients $(4.5 \%)$, doxepin 21 patients $(4.3 \%)$, dibenzepin 2 patients $(0.4 \%)$ and protriptyline one patient $(0.2 \%)$. Two patients took 2 different tricyclic drugs. None of them took butriptyline or desipramine, the other 2 antidepressants of this group available in the United Kingdom. Sixty-nine patients were reported to have ingested more than $1 \mathrm{~g}$ of drug; 160 between $250 \mathrm{mg}$ and $1 \mathrm{~g}$, and $104<250 \mathrm{mg}$. In 156 patients $(31.9 \%)$, however, the amount ingested was not known.

Two hundred and five patients $(41.9 \%$ ) took other drugs in addition to tricylcic antidepressants, benzodiazepines (105 patients) being the most common.

\section{Source of drugs}

Table 2 shows the relationship between age and source of tablets. Overall, 303 patients were reported to have taken drugs prescribed for themselves or for a relative. Adults most often took drugs intended for themselves, whilst children under the age of 5 years most frequently took tablets intended for a relative.

\section{Symptoms}

Symptoms were reported in 390 patients $(79 \cdot 8 \%)$. These were coma 164 patients $(33.5 \%)$, drowsiness 192 patients $(39.3 \%)$, delirium 19 patients $(3.9 \%)$,
TABLE 2. Relationship between age and source of tablets*

\begin{tabular}{lcccc}
\hline & \multicolumn{3}{c}{ Age (years) } \\
Source of tablets & $\leqslant 5$ & $6-14$ & $\geqslant 5$ & Total \\
\hline Prescribed for patient & 9 & 10 & 211 & 230 \\
Prescribed for relative & 52 & 7 & 14 & 73 \\
Neither & 19 & 3 & 17 & 39 \\
Not known & 12 & 5 & 127 & 144 \\
Total & 92 & 25 & 369 & 486 \\
\hline
\end{tabular}

* Excludes 3 patients whose age was not stated.

anti-cholinergic effects 47 patients $(9 \cdot 6 \%)$, respiratory depression 28 patients $(5.7 \%)$, respiratory arrest 6 patients $(1 \cdot 2 \%)$, convulsions 62 patients $(12.7 \%)$, repeated convulsions ( 3 or more) 39 patients $(8 \%)$, cardiac complications 141 patients $(28 \%)$ including sinus tachycardia 96 patients $(19.6 \%)$, tachydysrhythmias 17 patients $(3.5 \%)$, bradycardia 9 patients $(1.8 \%)$, hypotension 31 patients $(6.3 \%)$, and cardiac arrest 12 patients $(2.5 \%)$. Convulsions, cardiac complications and either respiratory depression or coma were seen together in 27 patients $(5 \cdot 5 \%)$.

The relationship between age and the frequency of symptoms is shown in Table 3 . The only major

TABLE 3. Relationship between age and incidence of symptoms

\begin{tabular}{lrrrr}
\hline & \multicolumn{4}{c}{ Age (years) } \\
& $\leqslant 5$ & $6-14$ & $\geqslant 15$ & Total \\
\hline No symptoms & 39 & 7 & 53 & 99 \\
Coma & 10 & 9 & 144 & 163 \\
Drowsiness & 33 & 9 & 149 & 191 \\
Delirium & 3 & 2 & 14 & 19 \\
Anti-cholinergic effects & 7 & 1 & 37 & 45 \\
Respiratory depression & 2 & 1 & 25 & 28 \\
Respiratory arrest & 1 & 0 & 5 & 6 \\
Convulsions & & & & \\
$\quad$ Present & 14 & 3 & 45 & 62 \\
$\quad$ Repeated & 9 & 1 & 29 & 39 \\
Cardiac complications & & & & \\
$\quad$ Present & 26 & 4 & 111 & 141 \\
$\quad$ Tachycardia & 17 & 4 & 75 & 96 \\
$\quad$ Tachydysrhythmia & 4 & 0 & 13 & 17 \\
$\quad$ Bradycardia & 2 & 0 & 7 & 9 \\
$\quad$ Hypotension & 4 & 1 & 26 & 31 \\
$\quad$ Cardiac arrest & 3 & 0 & 9 & 12 \\
Deaths & 3 & 0 & 13 & 16 \\
Total no. of patients & 92 & 25 & 369 & $486^{*}$ \\
\hline
\end{tabular}

* Excludes 3 patients whose age was not stated. 
TABLE 4. Relationship between drug ingested and incidence of symptoms*

\begin{tabular}{|c|c|c|c|c|c|c|c|c|c|c|}
\hline \multirow[b]{3}{*}{ Drug } & \multirow[b]{3}{*}{$\begin{array}{l}\text { No. of } \\
\text { patients }\end{array}$} & \multicolumn{8}{|c|}{ Symptoms } & \multirow[b]{3}{*}{ Deaths } \\
\hline & & \multirow[b]{2}{*}{$\begin{array}{l}\text { Convul- } \\
\text { sions }\end{array}$} & \multirow[b]{2}{*}{ Coma } & \multicolumn{6}{|c|}{ Cardiac complications } & \\
\hline & & & & Present & $\begin{array}{l}\text { Tachy- } \\
\text { cardia }\end{array}$ & $\begin{array}{c}\text { Tachy- } \\
\text { dysrhythmia }\end{array}$ & $\begin{array}{l}\text { Brady- } \\
\text { cardia }\end{array}$ & $\begin{array}{l}\text { Cardiac } \\
\text { arrest }\end{array}$ & $\begin{array}{l}\text { Hypo- } \\
\text { tension }\end{array}$ & \\
\hline Amitriptyline & (203) & 16 & 89 & 59 & 39 & 9 & 4 & 5 & 14 & 9 \\
\hline Dothiepin & $(70)$ & 12 & 24 & 18 & 17 & 1 & 0 & 0 & 2 & 1 \\
\hline Imipramine & (68) & 14 & 20 & 22 & 14 & 2 & 2 & 2 & 5 & 2 \\
\hline Maprotiline & (48) & 12 & 12 & 11 & 6 & 2 & 2 & 2 & 2 & 1 \\
\hline Nortriptyline & (27) & 6 & 11 & 9 & 5 & 2 & 0 & 1 & 2 & 0 \\
\hline Trimipramine & (27) & 0 & 8 & 6 & 5 & 0 & 1 & 0 & 2 & 0 \\
\hline Clomipramine & (22) & 0 & 4 & 6 & 4 & 0 & 0 & 1 & 1 & 1 \\
\hline Doxepin & (21) & 0 & 6 & 7 & 4 & 0 & 0 & 7 & 4 & 1 \\
\hline
\end{tabular}

* Excludes 2 patients who took dibenzepin and one patient who took protriptyline.

differences were that patients aged more than 15 years had a higher incidence of coma $(39 \%)$, compared with those under 5 years $(10.9 \%)$, and that $42.4 \%$ of children were asymptomatic compared with only $14.4 \%$ of adults.

The relationship between the antidepressant ingested and the frequency of symptoms is shown in Table 4. The only major difference was seen in the incidence of convulsions where $25 \%$ of patients ingesting maprotiline developed this complication but none of the patients taking clomipramine, trimipramine or doxepin did so. Overall, however, there were no statistically significant differences between individual antidepressants.

\section{Treatment}

Anticonvulsants were used in 52 instances (diazepam 33 patients, phenobarbitone 8 patients, phenytoin 5 patients, paraldehyde 4 patients, chlormethiazole 2 patients); antiarrhythmic agents were used in 10 cases (lignocaine 7 patients, atropine 2 patients, practolol one patient); catecholamines were used in 9 patients (isoprenaline 5 patients, adrenaline 2 patients and dopamine 2 patients); chlorinesteraseinhibitors were used in 21 cases (pyridostigmine 10 patients, neostigmine 6 patients, physostigmine 5 patients). Eighteen patients received artificial ventilation. The treatment listed above exclude those used during cardiac arrest procedures. In no less than 357 patients, however, no treatment was recorded as having been given.

\section{Outcome}

Sixteen $(3.3 \%)$ of the patients died. Psychiatric assessment was made in 99 of those who recovered, $34(7.0 \%)$ being admitted to psychiatric units and 21 patients $(4 \cdot 3 \%)$ discharging themselves. The drugs involved in the fatal cases were amitriptyline
( 9 patients) imipramine ( 2 patients) and clomipra- $\$$ mine, maprotiline, doxepin, dothiepin and dibenzepin (one patient each).

\section{Discussion}

All the published series of tricyclic antidepre $\vec{\rho} \vec{c}$ sant poisoning have been in patients admitted either $\frac{\mathbb{D}}{8}$ to Poisons Treatment Centres or to Units with $\mathbb{Q} \mathbb{\mathbb { Q }}$ special interest in this problem. Comparison wiष these results is difficult because the authors believe $\mathbb{Q}$ their sample represented a cross-section of patiens in terms of age, severity of poisoning, drugs ingested and hospital where treated. The epidemiologicat findings in this series were no different from the general pattern of poisoning with peak incidences amongst young children and women aged 15-35 years. The high proportion of older children (5-15 years) who took their own tablets was surprising. In recent years, deliberate poisoning has increased in $\overrightarrow{\overrightarrow{0}}$ this age group and in one children's hospital the $\exists$ number of admissions for this reason has increased by 7.5 times over the last 10 years (Broadhead, 1978). Clearly, if antidepressants are to be prescribed for depression in childhood then parents must be warned of their dangers and must supervise their administration.

Over $40 \%$ of the children in this survey could have ingested only trivial amounts of drug for they were reported to have remained symptom free. The 옹 incidence of significant toxicity in childhood poison- $\rightarrow$ ing as a whole is low, Broadhead reporting that less than one in 10 of children admitted to hospital for $N$ poisoning was in fact suffering from an adverse reaction (Broadhead, 1978). It seems likely that a considerable number of children could have been $\mathrm{\omega}$ observed at home and thus spared hospital admission In the case of tricyclic antidepressants it is probablyo safe to allow a child home if he remains unaffected 
$6 \mathrm{hr}$ after an alleged overdose. However, if a slowrelease preparation is implicated then a 12 -hr observation is desirable.

The authors were unable to show any statistically significant differences between the toxicity of individual antidepressants although overdose of amitriptyline-like drugs resulted in a significantly higher incidence of coma than overdose of imipramine and its analogues $(P<0.01)$. This difference may have been because patients taking amitriptyline-like drugs ingest larger quantities than patients taking imipramine-like drugs, or because amitriptyline and its congeners are intrinsically more toxic. Unfortunately the information on the amounts of drug ingested was insufficiently detailed to allow the authors to conclude which of these explanations was correct. In only one of the published series has it been suggested that there were differences between the individual antidepressants. Among 153 patients reported by Thorstrand (1976), all 4 patients taking dibenzepin died. In the present series only 2 patients took this drug, so that definite conclusions are not possible, although one patient did die. It has also been suggested that doxepin is less cardiotoxic than other drugs because it does not prolong intraventricular conduction (Burrows et al., 1976) although a similar incidence was found of cardiotoxicity with this drug compared with the others.

Park and Proudfoot (1977) have reported a high incidence of coma and convulsions in maprotiline overdosage and in the present series $25 \%$ of the patients taking this drug developed these complications. Recently, there have been reports of convulsions occurring during the therapeutic use of this drug (Shepherd and Kerr, 1978; Hall and Russell, 1978). Because of the high incidence of convulsions in their series, the authors decided to extend their survey. Up to July 1978 , a total of 75 cases had been documented of which $22(29.4 \%)$ patients were unconscious, $15(20 \%)$ had convulsions, $9(12 \%)$ sinus tachycardia, $4(5.3 \%)$ bradycardia, $3(4 \%)$ cardiac arrest, $2(2.3 \%)$ hypotension and 2 patients $(2.3 \%)$ died. The proportion of patients exhibiting convulsions is lower than in the original study $(25 \%)$ but still higher than the overall percentage in the 489 patients $(12 \cdot 7 \%)$. Maprotiline is available in 5 tablet strengths ranging from 10 to $150 \mathrm{mg}$ and this made it impossible to determine whether the high incidence of convulsions was due to the patients ingesting excessively large amounts of drug, since it has been suggested that convulsions may result from therapeutic use of high doses of this drug (Burley, Jukes and Steen, 1978; Hall and Russell, 1978; Shepherd and Kerr, 1978). The authors are unable to say whether maprotiline is intrinsicially more toxic than the other tricyclic antidepressants but their study of this drug is continuing.
The number of patients reported to have received no treatment was higher than expected (357 patients, $73 \%$ ). This probably reflects the attitude of doctors who do not regard the supportive care these patients receive as 'treatment'.

In a recent survey of the use of drugs in general practice (Skegg, Doll and Perry, 1977) it was found that in a single year, $11.2 \%$ of middle-aged women received antidepressant medication. With this number of prescriptions it is not surprising that overdose is a common problem. The present study shows that it is also a significant clinical problem with a substantial proportion of both adults and children developing serious symptoms such as coma, convulsions, and myocardial depression. It would be prudent for doctors prescribing these drugs to warn patients and relatives of their dangers, to monitor response to treatment at regular intervals and to issue repeat prescriptions only if the drug is still needed and the patient is actually taking it. For someone with suicidal inclinations or with a past history of parasuicide, it may prove wiser to prescribe one of the more recently introduced antidepressants such as mianserin, nomifensine and flupenthixol if further studies confirm the initial reports suggesting that they are less toxic when taken in overdose. (Crome et al., 1978; Montgomery, Crome and Braithwaite, 1978).

\section{Acknowledgments}

We would like to thank all those physicians who kindly completed our questionnaires, Dr R. Goulding and Dr G. N. Volans for their advice on the preparation of this report and Mr G. Kimber for his help with the analysis of the data.

\section{References}

Biggs, J.T., Spiker, D.G., Petit, J.M. \& Zeigler, V. E. (1977) Tricyclic antidepressant overdose. Incidence of symptoms. Journal of the American Medical Association, 238, 135.

Bismuth, C., Pebay-Peyroula, F., Fréjaville, J.P., EfthyMIOU, M.L. \& FourNIER, E. (1969) 245 nouveaux cas d'intoxication aiguë par les dérivés tricycliques. Traitement par les sels de sodium. European Journal of Toxicology, 6, 285.

Broadhead, R.L. (1978) Archives of Disease in Childhood (submitted for publication).

Brown, T.C.K., Dwyer, M.E. \& Stocks, J.G. (1971) Antidepressant overdosage in children-a new menace. Medical Journal of Australia, 2, 848.

Burley, D., Jukes, A. \& Steen, J. (1978) Maprotiline hydrochloride and grand-mal seizures. British Medical Journal, 2, 1230.

Burrows, G.D., Vohra, J., Hunt, J., Slowman, J.G., Scoggins, B.A. \& Davies, B. (1976) Cardiac effects of different tricyclic antidepressant drugs. British Journal of Psychiatry, 129, 335.

Christensen, K.N. \& Andersen, H.H. (1977) Deliberate poisoning with tricyclic antidepressants treated in an intensive care unit. Acta pharmacologica et toxicologica, 41 (suppl. 2), 511. 
Crome, P., Braithwaite, R.A., Newman, B. \& MontGOMERY, S. (1978) Choosing an antidepressant. British Medical Journal, 1, 859.

FourNIER, E. (1973) Intoxications par les antidépresseurs tricycliques. Thérapie, 28, 307.

Fréjaville, J.P., Efthymiou, M.L., Mellerio, F., Fournier, E., Gervais, P., Gorceix, A., Proteau, J. \& Gaultier, M. (1965) Cent cas d'intoxication aiguë par les dérivés de l'iminodibenzyle (imipramine, amitriptyline et trimépramine). Société Médicale des Hôpitaux de Paris, 116, 927.

Fréjaville, J.P., Nicaise, A.M., Christoforov, B., Sraer, J.D., Pebay-Peyroula, F. \& Gaultier, M. (1966) Etude statistique d'une seconde centaine d'intoxications aigüe par les dérivés de l'imionodibenzyle (Tofranil, Pertofran, G34, Surmontil) et ceux du dihydrobenzocyclohéptadiene (Laroxyl, Elavil). Société Médicale des Hópitaux de Paris, $117,1151$.

Goel, K.M. \& Shanks, R.A. (1974) Amitriptyline and imipramine poisoning in children. British Medical Journal, 1, 261.

Hall, M.J., Russell, R.I. (1978) Maprotiline hydrochloride and grand-mal seizures. British Medical Journal, 2, 961.

KunN, R. (1958) The treatment of depressive states with G22355 (imipramine hydrochloride). American Journal of Psychiatry, 114, 459.

Montgomery, S., Crome, P. \& Braithwaite, R.A. (1978) Nomifensine overdose. Lancet, 1, 828.

Noble, J. \& Matthew, H. (1969) Acute poisoning by tricyclic antidepressants: clinical features of 100 patients. Clinical Toxicology, 2, 403.
Noto, R., Robert, J. \& Hanote, P. (1970) Traitment d'urgence et transport des intoxications aigües par les dérivés imipraminiques. Agressologie, 11, 515.

Park, J. \& PROUdfoot, A.T. (1977) Acute poisoning with maprotiline hydrochloride. British Medical Journal, 1, 1573.

Pinder, R.M., Brogden, R.N., Speight, T.M. \& Avery, G.S. (1977) Maprotiline: a review of its pharmacological $\stackrel{\overrightarrow{9}}{\rightarrow}$ properties and therapeutic efficacy in mental depressive states. Drugs, 13, 321.

Proudfoot, A.T. \& PARK, J. (1978) Changing patterns of drugs used for self-poisoning. British Medical Journal, $1, \frac{\Omega}{7}$ 90.

Sedal, L., Korman, M.G., Williams, P.O. \& Mushin, G. (1972) Overdosage of tricyclic antidepressants. A report of $\bar{c}$ two deaths and a prospective study of 24 patients. Medical $\overrightarrow{0}$ Journal of Australia, 2, 74.

Serafimoviki, M., Thorball, N., Asmussen, I. \& Lunding, $\overrightarrow{\vec{\omega}}$ M. (1975) Tricyclic antidepressive poisoning with special reference to cardiac complications. Acta anaesthesiologica scandinavica, 57 (Suppl.), 55.

ShePherd, G.A.A. \& KerR, F. (1978) Maprotiline hydro- 3 chloride and grand-mal seizures. British Medical Journal, of $1,1523$.

SkegG, D.C.G., Doll, R. \& Perry, J. (1977) Use of medicines in general practice. British Medical Journal, 1, 1561.

Thorstrand, C. (1976) Clinical features in poisoning by of tricyclic antidepressants with special reference to the ECG. $\infty$ Acta medica scandinavica, 199, 337. 